\title{
Characterization of PAHs Contamination in Soils from Metropolitan Region of Northern China
}

\author{
Min Qiao · Chao Cai $\cdot$ Yi-zong Huang • \\ Yun-xia Liu $\cdot$ Ai-jun Lin $\cdot$ Yuan-ming Zheng
}

Received: 1 December 2009/ Accepted: 9 July 2010/Published online: 21 July 2010

(C) Springer Science+Business Media, LLC 2010

\begin{abstract}
The present study characterized the distribution, sources as well as carcinogenic potency of PAHs in surface soil from metropolitan region of northern China. The total PAHs in topsoil ranged from 322.6 to $23244.7 \mu \mathrm{g} \mathrm{kg}^{-1}$. The mean and median concentrations of 16 PAHs were 1040.8 and $626.7 \mu \mathrm{g} \mathrm{kg}^{-1}$, respectively. Source analysis revealed that pyrogenic sources played a major role at the locations and pyrogenic PAHs were mainly from incomplete combustion of coal, biomass and petroleum. The calculated mean BaP-equivalent values for individual carcinogenic PAHs were $148.4 \mu \mathrm{g} \mathrm{kg}^{-1}$.
\end{abstract}

Keywords Soil · PAH - Spatial distribution · Sources

Polycyclic aromatic hydrocarbons (PAHs) are widely spread in all the compartments of the environment. Forest fires, volcanoes and microbial metabolism are the predominant natural sources. However, most of the PAHs are originated from anthropogenic activities, such as fuel spills, combustion of fuels, coal and wood (Srogi 2007). Especially in megacities, larger emissions of PAHs were

M. Qiao $(\bowtie)$ · Y.-z. Huang · Y.-x. Liu · Y.-m. Zheng

Research Center for Eco-Environmental Sciences, Chinese

Academy of Sciences, 100085 Beijing, China

e-mail: minqiao@rcees.ac.cn

C. Cai

Institute of Urban Environment, Chinese Academy of Sciences, 361003 Xiamen, China

A.-j. Lin

Department of Environmental Engineering, Beijing University

of Chemical Technology, 100029 Beijing, China observed due to the accelerated urbanization and highdensity traffic condition (Tuntawiroon et al. 2007).

Due to their stable chemical structure and hydrophobic nature, PAHs are generally found adsorbed to particulate matter in air and water, and tend to accumulate in sediment, soil or biota. Thus, although most PAHs are emitted to the atmosphere, the airborne PAHs can eventually reach the top layer of the soil to become adsorbed by soil colloids and absorbed by soil organisms (Srogi 2007). Soils could be regarded as natural sinks for PAHs. Because of the notable carcinogenic and mutagenic properties, PAHs present in the soil environment can exhibit ecotoxic effects on the development of soil organisms and create threats to the soil habitat function even at low levels. It is also of great concern because the contaminated soils can create a risk to humans through direct contact or through its introduction into the human food chain.

Megacities are considered more vulnerable with the large population and limited land resources. Therefore, it is important to evaluate the spatial distribution and apportion the sources of PAHs in soils from megacities, then to assess the potential risk of soil contamination with PAHs. The present study was carried out on a regional scale to survey the soil PAHs contamination in a mega-metropolitan region in northern China including Beijing, Tianjin and parts of the Hebei province. As we known, Beijing is the capital of the People's Republic of China. Tianjin, one of the four municipalities of China, is the largest coastal city open to the outside world in northern China. The megametropolitan region of Beijing-Tianjin-Hebei presently accounts for $11 \%$ of the country's gross domestic product (GDP), however, environmental pollution has become a serious problem with the rapid development of industrialization and urbanization. Although PAHs concentrations have been reported in part of this area (Zuo et al. 2007), our 
knowledge of the general contamination pattern and environmental risk in this mega-metropolitan region is still inadequate. This study presents an overview of the distribution pattern and source assignment of 16 EPA PAHs in soil samples and gives insights into the potential risk of this metropolitan region.

\section{Materials and Methods}

The study area includes Beijing, Tianjin and parts of the Hebei province, covering an area about $64,400 \mathrm{~km}^{2}$ (Fig. 1). There were totally 180 soil samples were collected in July 2007 and the sampling depth was $0-20 \mathrm{~cm}$. At each site, about 5 cores were bulked together to form one sample. The samples were air-dried at room temperature and were ground and sieved with a 60-mesh sieving screen. All results were reported as dried weight basis.

About $5 \mathrm{~g}$ soil samples were mixed with anhydrous sodium sulfate and activated copper powder. Samples were extracted by accelerated solvent extraction (Dionex ASE $300)$ with acetone/dichloromethane solvent $(1: 1 / \mathrm{v} / \mathrm{v})$. The extracts were cleaned up via silica gel/alumina column and PAHs fraction was obtained by elution with $70 \mathrm{~mL}$ of a mixture of hexane/dichloromethane $(7: 3, \mathrm{v} / \mathrm{v})$. The samples were analyzed by GC/MS (Agilent 7890 GC, 5975 MSD) in selected ion monitoring (SIM) modes and quantified by internal calibration method. Detailed description of clean up and analysis were described elsewhere (Qiao et al. 2006). PAHs studied were naphthalene (Nap), acenaphthylene (Acy), acenaphthene (Ace), fluorine (Fl), phenanthrene

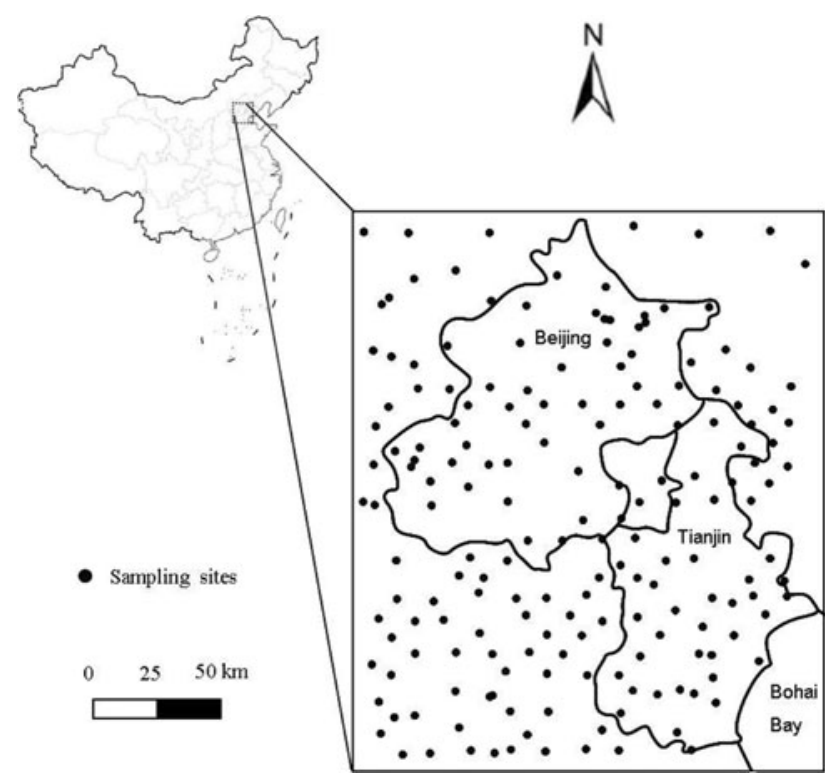

Fig. 1 Sampling sites of surface soil in Beijing, Tianjin and the surrounding regions in China
(Phe), anthracene (An), fluoranthene (Flu), pyrene (Pyr), benzo[a]anthracene $(\mathrm{BaA})$, chrysene $(\mathrm{Chr})$, benzo[b]fluoranthene $(\mathrm{BbF})$, benzo[k]fluoranthene $(\mathrm{BkF})$, benzo[a]pyrene $(\mathrm{BaP})$, indeno[1,2,3-cd]pyrene (InP), dibenzo[a,h]anthracene (DBA), and benzo[ghi]perylene (BgP).

All data were subject to strict quality control procedures. Recovery ranged from $53.8 \pm 4.9 \%$ to $117.2 \pm 7.5 \%$ with a mean value of $94.0 \pm 8.3 \%$ for the 16 PAHs. The detection limits were $1.7-4.9 \mu \mathrm{g} \mathrm{kg}^{-1}$. Procedure blanks were run simultaneously with every set of samples and were subtracted from the analytical results.

Statistical analyses including principal component analysis among variables were conducted using the software SPSS 11.5 for Windows. Kriging interpolation and contour maps were constructed with Surfer 8.0 (Golden Software, Co., USA).

\section{Results and Discussion}

The total PAHs in topsoil of the study area ranged from 322.6 to $23244.7 \mu \mathrm{g} \mathrm{kg}^{-1}$, and the mean concentration of 16 PAHs was $1040.8 \mu \mathrm{g} \mathrm{kg}^{-1}$. Concentrations of individual PAHs exhibited a rather high variability with a mean coefficient of variation $(\mathrm{CV})$ value of 1.8. The median value of $626.7 \mu \mathrm{g} \mathrm{kg}^{-1}$ was considered more appropriate for the assessment of the mean concentration of $16 \mathrm{PAHs}$ in this area because of their non-normal distribution. High molecular weight PAHs with 4-6 rings were the major fractions of the total PAHs in topsoil with an average proportion of $71 \%$. Maliszewska-Kordybach classified soil PAHs contamination into 4 categories, namely not contaminated $\left(<200 \mu \mathrm{g} \mathrm{kg}^{-1}\right)$, weakly contaminated (200-600 $\mu \mathrm{g} \mathrm{kg}^{-1}$ ), contaminated (600-1,000 $\mu \mathrm{g} \mathrm{kg}^{-1}$ ), and heavily contaminated $\left(>1,000 \mu \mathrm{g} \mathrm{kg}^{-1}\right.$ ) (Maliszewska-Kordybach 1996). According to this classification, the concentrations obtained in this study present $46 \%$ of the samples as 'weakly contaminated', $37 \%$ as 'contaminated' and $17 \%$ as 'heavily contaminated'. Observed median concentration of $\sum 16$ PAHs $\left(626.7 \mu \mathrm{g} \mathrm{kg}^{-1}\right)$ were comparable to the mean PAHs concentration of $611 \mu \mathrm{g} \mathrm{kg}^{-1}$ in Tokushima of Japan (Yang et al. 2002) and the median concentration of $704 \mu \mathrm{g} \mathrm{kg}^{-1}$ in urban soil of Torino, Italy (Morillo et al. 2007). The concentration was higher than those in soil from Hong Kong (median of $140 \mu \mathrm{g} \mathrm{kg}^{-1}$ ) (Chung et al. 2007) and urban soil in Switzerland (median of $451 \mu \mathrm{g} \mathrm{kg}^{-1}$ ) (Bucheli et al. 2004). In contrast, PAHs concentrations in soil from Glasgow, UK (median of $8337 \mu \mathrm{g} \mathrm{kg}^{-1}$, mean of $11930 \mu \mathrm{g} \mathrm{kg}^{-1}$, Morillo et al. 2007) were higher than those obtained in this study.

Ordinary kriging interpolation was applied to visualize the spatial distribution of PAHs in topsoil in the study area since it can provide theoretically optimal estimates without 
bias and with minimal and known variance. The relatively high concentration levels were found in Tianjin and Beijing urban or peri-urban area (Fig. 2). Another hotspot located on the north of Tianjin where was associated with mining activity in the last several decades. It clearly indicates the influence of human activities on PAHs levels of soils.

To assess and reduce the environmental risk of PAHs, it is essential to identify the potential sources. Isomeric ratios of PAHs are known to provide reliable estimation of the emission sources of PAHs. An/(An + Phe) and Flu/(Flu + Pyr) are frequently used PAH ratios to separate petrogenic and pyrogenic sources (Yunker et al. 2002) PAHs originated from petrogenic sources are characterized by the ratios of $\mathrm{An} /(\mathrm{An}+\mathrm{Phe})<0.1$ and $\mathrm{Flu} /(\mathrm{Flu}+\mathrm{Pyr})<0.4$. Accordingly, the ratio of $\mathrm{An} /(\mathrm{An}+\mathrm{Phe})>0.1$ implies the dominance of combustion. The ratio of $\mathrm{Flu} /(\mathrm{Flu}+$ Pyr) $>0.5$ indicates the source of biomass and coal combustion, while the ratio between 0.4 and 0.5 are characteristic of liquid fossil fuel (vehicle and crude oil) combustion. Furthermore, $\mathrm{BaA} /(\mathrm{BaA}+\mathrm{Chr})$ and $\mathrm{InP} /$ $(\mathrm{InP}+\mathrm{BgP})$ are also used to distinguish between petrogenic and pyrolytic sources. Yunker et al., suggested that a $\mathrm{BaA} /(\mathrm{BaA}+\mathrm{Chr})$ or $\mathrm{InP} /(\mathrm{InP}+\mathrm{BgP})$ ratio less than 0.2 indicates petroleum source. A ratio of $\mathrm{BaA} /(\mathrm{BaA}+$ Chr) $>0.35$ accounts for combustion of coal, grass and wood, while the ratio between 0.2 and 0.35 accounts for petroleum combustion. The ratio of $\mathrm{InP} /(\mathrm{InP}+\mathrm{BgP})>$ 0.5 is characteristic of grass, wood or coal combustion, from 0.2 to 0.5 indicates liquid fossil fuel combustion (Yunker et al. 2002). In this study, these molecular markers were interpreted in concert and checked for consistency to identify the possible PAHs sources of soil samples. In cross plots (Fig. 3), An/(An + Phe) ratios in all soil samples are more than 0.1, and Flu/(Flu + Pyr) ratios in most of soil samples are in the combustion section irrespective of

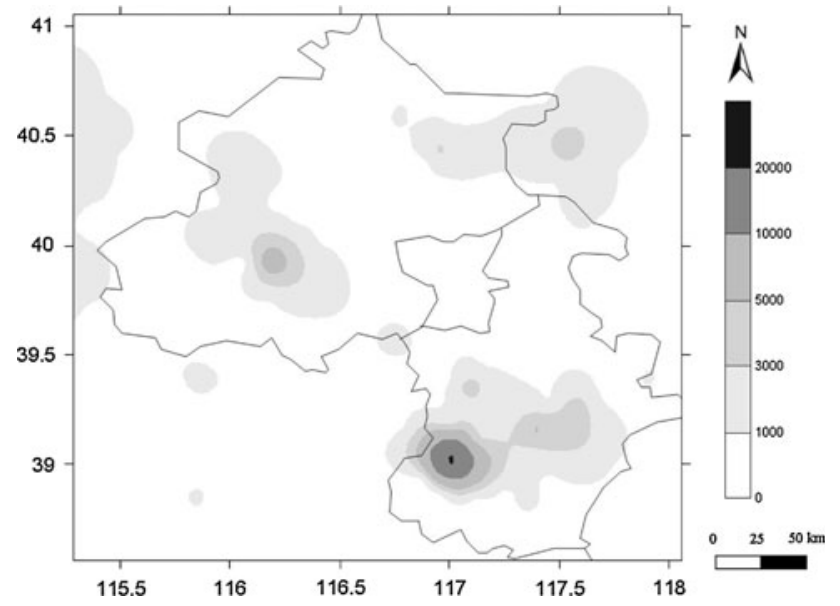

Fig. 2 Spatial distribution of PAH concentrations for $16 \mathrm{PAHs}$ $\left(\mu \mathrm{g} \mathrm{kg}^{-1}\right)$ petroleum combustion or biomass \& coal combustion. The ratio of $\mathrm{BaA} /(\mathrm{BaA}+\mathrm{CHR})$ ranged from 0.18 to 0.64 , with $59 \%$ of the values larger than 0.35 and $41 \%$ of the values falling between 0.2 and 0.35 , which suggests that the majority of PAHs in the topsoil originated from combustion. As shown in the cross plot (Fig. 3), the values of InP/ $(\mathrm{InP}+\mathrm{BgP})$ varied between 0.25 and 0.67 , confirmed the soils were mainly suffered from mixed source of both biomass/coal combustion and petroleum combustion.

PCA was also performed to examine the sources of PAHs pollution in soils. Two factors with eigenvalues over 1 were extracted after applying the Varimax rotation and
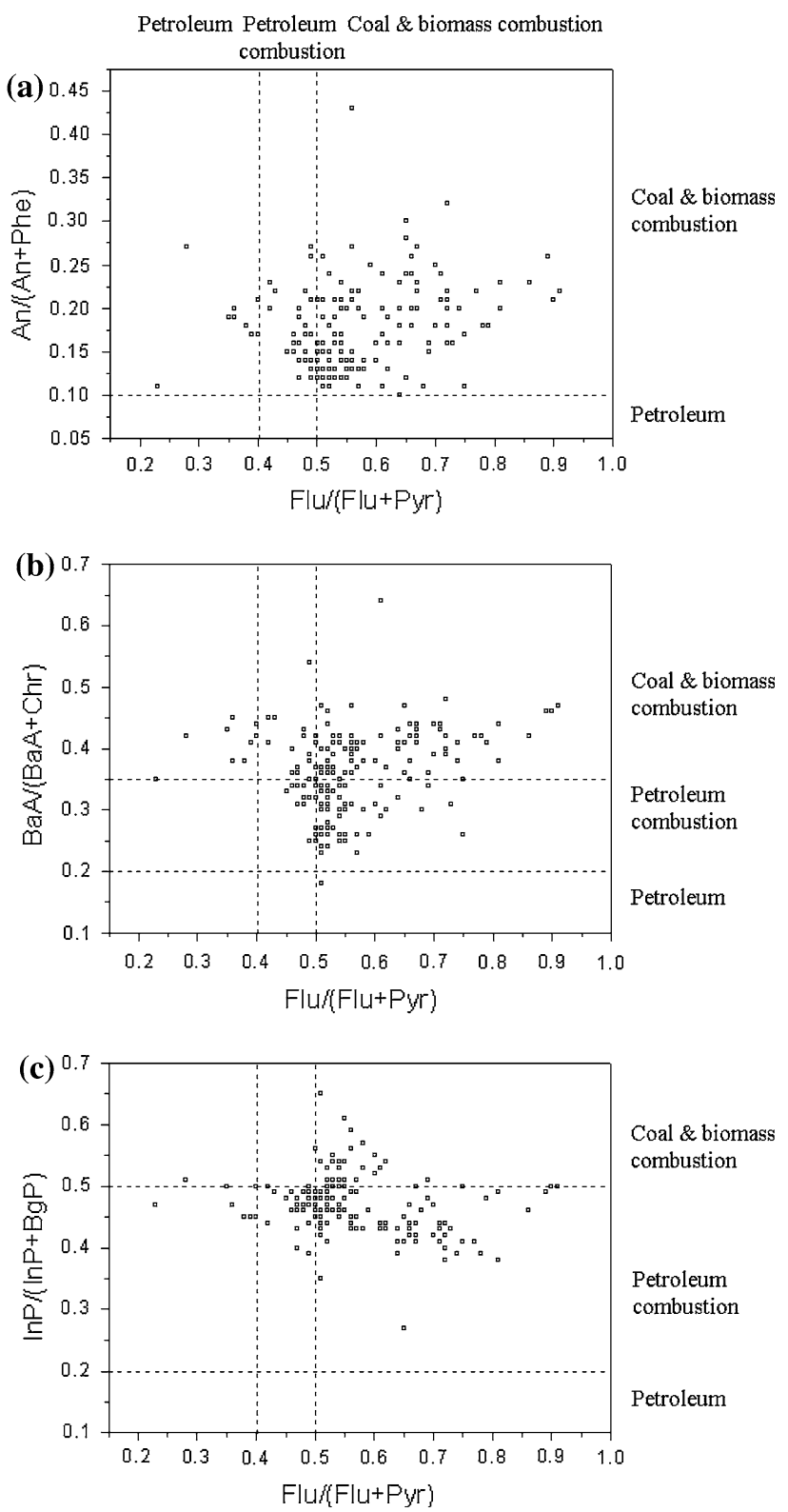

Fig. $3 \mathrm{PAH}$ cross plots a $\mathrm{An} /(\mathrm{An}+\mathrm{Phe})$ versus $\mathrm{Flu} /(\mathrm{Flu}+\mathrm{Pyr})$, b $\mathrm{BaA} /(\mathrm{BaA}+\mathrm{Chr})$ versus $\mathrm{Flu} /(\mathrm{Flu}+\mathrm{Pyr})$, c $\mathrm{InP} /(\mathrm{InP}+\mathrm{BgP})$ versus Flu/(Flu + Pyr) 
were able to explain $89 \%$ of the total variance. PC1 was strongly correlated with the higher molecular mass compounds, including Flu, Pyr, BaA, Chr, BbF, BkF, BaP, InP, DBA and BgP. PC 2 was dominated by low ring compounds including Nap, Ace, Fl, Phe and An. The different structures of the high and low ring PAH compounds could be attributed to the different sources and physico-chemical and biological characteristics of these compounds (Agarwal 2009). The loading plot of PCA was exhibited in Fig. 4. Some researches have reported Flu, Pyr, BaA, Chr, BbF, $\mathrm{BkF}$ and $\mathrm{BaP}$ as predominant in coal combustion profiles (Larsen and Baker 2003). Both BgP and InP have been identified as typical tracers of vehicle emissions (Fraser et al. 1997). DBA predominates in gasoline engine exhaust tar (Fraser et al. 1997). Therefore, PC1 was regarded as the combined coal combustion and vehicular emission source. Fl, Phe and An are indicators for coke production. Nap accounted for the majority of the mass in coke oven, highway tunnel and gasoline engine samples (Khalili et al. 1995). Thus, PC2 was considered as coke oven sources. As shown in the cross plot of Fig. 4, Acy was separated from other compounds, suggesting other contribution sources exist. Acy has been reported to be a tracer for domestic wood combustion or vehicular emission (Jiang et al. 2009). Biomass combustion could be a possible explanation for the unidentified source since it is very common in north China to burn crop straw in the pen air after crop harvesting (Cao et al. 2008). The PCA results were consistent with the isomeric ratio analysis that coal/biomass combustion and petroleum combustion were the main contributors of PAHs accumulation in topsoil of Beijing, Tianjin and the surrounding regions.

The United States Environmental Protection Agency (USEPA) has classified seven PAHs including $\mathrm{BaA}, \mathrm{Chr}$, $\mathrm{BbF}, \mathrm{BkF}, \mathrm{BaP}, \mathrm{InP}$ and $\mathrm{DBA}$ as Group $\mathrm{B} 2$, probable

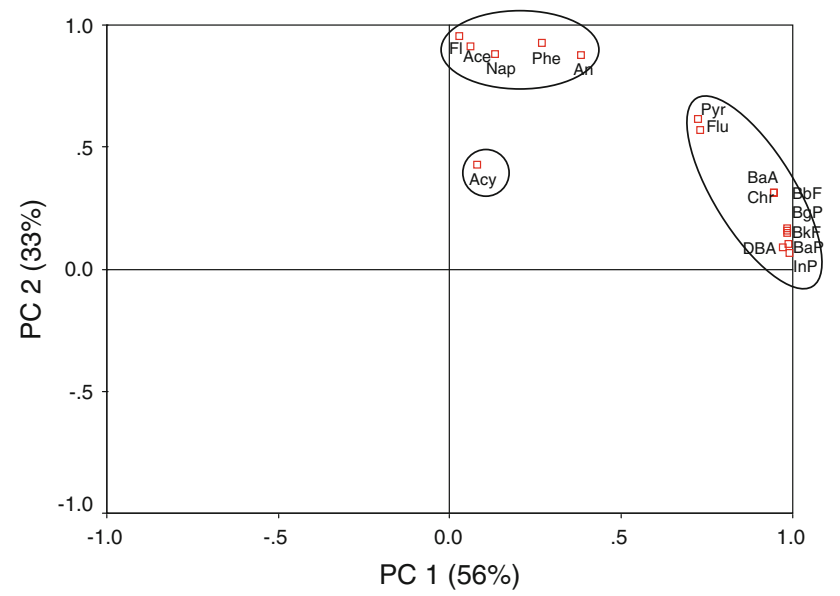

Fig. 4 Principal component analyses loading plot for individual components of PAHs human carcinogens. The concentrations of these seven carcinogenic PAHs were from 139.3 to $17768.8 \mu \mathrm{g} \mathrm{kg}^{-1}$ and the percentage was from 24 to $76 \%$. At present, no PAHs guideline values in soil are available in China. To assess the hazard of PAHs contaminated soil, toxic equivalency factors (TEFs) were used to quantify the benzo[a]pyrene-equivalent concentration (BaPeq). The carcinogenic potencies of individual carcinogenic PAHs were calculated by multiplying their concentration with the corresponding TEF. The total carcinogenic potency was estimated by the sum of each BaPeq. TEFs compiled by Tsai et al. (2004) were adopted to calculate BaPeq. Calculated total BaPeq concentrations varied from 35.9 to $5415.5 \mu \mathrm{g} \mathrm{kg}^{-1}$. The mean and median BaPeq concentrations were 148.4 and $81.8 \mu \mathrm{g} \mathrm{kg}^{-1}$, respectively. Although the highest BaPeq was even higher than that in traffic soil of India (1,009 $\mathrm{g} \mathrm{kg}^{-1}$ ) (Agarwal 2009), the average or median BaPeq was lower than those in Shanghai urban soil (428 $\mathrm{g} \mathrm{kg} \mathrm{k}^{-1}$ ) (Jiang et al. 2009) from China. The BaPeq was comparable to that in industrial soil $\left(124 \mu \mathrm{g} \mathrm{kg}^{-1}\right)$ and residential soil $\left(96 \mu \mathrm{g} \mathrm{kg}^{-1}\right)$ from Tarragona County of Spain (Nadal et al. 2004). The major contributors to BaPeq are $\mathrm{BaP}, \mathrm{DbA}, \mathrm{BbF}, \mathrm{InP}$ and $\mathrm{BkF}$, accounting for $47,29,8$, 6 and $5 \%$ on average, respectively. The soil PAHs contamination of this study was found to be low to moderate on the global scale. The city centers or sites close to any other contamination source present higher amounts of PAHs.

Acknowledgments We gratefully acknowledge support for the research from the National Natural Science Foundation of China (20807053), the Ministry of Science and Technology, China (2007 CB407301) and Chinese Academy of Sciences (KZCX1-YW-06-03).

\section{References}

Agarwal T (2009) Concentration level, pattern and toxic potential of PAHs in traffic soil of Delhi, India. J Hazard Mater 171:894-900

Bucheli TD, Blum F, Desaules A, Gustafsson Ö (2004) Polycyclic aromatic hydrocarbons, black carbon, and molecular markers in soils of Switzerland. Chemosphere 56:1061-1076

Cao G, Zhang X, Wang Y, Zheng F (2008) Estimation of emissions from field burning of crop straw in China. Chin Sci Bull 53:784-790

Chung MK, Hu R, Cheung KC, Wong MH (2007) Pollutants in Hong Kong soils: polycyclic aromatic hydrocarbons. Chemosphere 67:464-473

Fraser MP, Cass GR, Simoneit BRT, Rasmussen RA (1997) Air quality model evaluation data for organics.4. C2-C36 nonaromatic hydrocarbons. Environ Sci Technol 31:2356-2367

Jiang YF, Wang XT, Wang F, Jia Y, Wu MH, Sheng GY, Fu JM (2009) Levels, composition profiles and sources of polycyclic aromatic hydrocarbons in urban soil of Shanghai, China. Chemosphere 75:1112-1118

Khalili NR, Scheff PA, Holsen TM (1995) PAH source fingerprints for coke ovens, diesel and, gasoline engines, highway tunnels, and wood combustion emissions. Atmos Environ 29:533-542 
Larsen RK, Baker JE (2003) Source apportionment of polycyclic aromatic hydrocarbons in the urban atmosphere: a comparison of three methods. Environ Sci Technol 37:1873-1881

Maliszewska-Kordybach B (1996) Polycyclic aromatic hydrocarbons in agricultural soils in Poland: preliminary proposals for criteria to evaluate the level of soil contamination. Appl Geochem 11:121-127

Morillo E, Romero AS, Maqueda C, Madrid L, Ajmone-Marsan F, Grcman H, Davidson CM, Hursthouse AS, Villaverde J (2007) Soil pollution by PAHs in urban soils: a comparison of three European cities. J Environ Monit 9:1001-1008

Nadal M, Schuhmacher M, Domingo JL (2004) Levels of PAHs in soil and vegetation samples from Tarragona County, Spain. Environ Pollut 132:1-11

Qiao M, Wang C, Huang S, Wang D, Wang Z (2006) Composition, sources, and potential toxicological significance of PAHs in the surface sediments of the Meiliang Bay, Taihu Lake, China. Environ Int 32:28-33

Srogi K (2007) Monitoring of environmental exposure to polycyclic aromatic hydrocarbons: a review. Environ Chem Lett 5:169-195
Tsai PJ, Shih TS, Chen HL, Lee WJ, Lai CH, Liou SH (2004) Assessing and predicting the exposures of polycyclyic aromatic hydrocarbons (PAHs) and their carcinogenic potencies from vehicle engine exhausts to highway toll station worker. Atmos Environ 38:333-343

Tuntawiroon J, Mahidol C, Navasumrit P, Autrup H, Ruchirawat M (2007) Increased health risk in Bangkok children exposed to polycyclic aromatic hydrocarbons from traffic-related sources. Carcinogenesis 28:816-822

Yang Y, Zhang X-X, Korenaga T (2002) Distribution of Polynuclear Aromatic Hydrocarbons (PAHs) in the Soil of Tokushima, Japan. Water Air Soil Poll 138:51-60

Yunker MB, Macdonald RW, Vingarzan R, Mitchell RH, Goyette D, Sylvestre S (2002) PAHs in the Fraser River basin: a critical appraisal of PAH ratios as indicators of PAH source and composition. Org Geochem 33:489-515

Zuo Q, Duan YH, Yang Y, Wang XJ, Tao S (2007) Source apportionment of polycyclic aromatic hydrocarbons in surface soil in Tianjin, China. Environ Pollut 147:303-310 